\title{
Microbiota fúngica em amostras de água potável e esgoto doméstico
}

\section{Fungal microbiota in drinking water and domestic sewage}

\author{
Tayana Sessegolo ${ }^{1}$; Camila Tochetto ${ }^{1}$; Régis Adriel Zanette ${ }^{2}$; \\ Aleksandro Schafer da Silva²; Sydney Hartz Alves; \\ Silvia Gonzalez Monteiro ${ }^{3 *}$; Janio Morais Santurio ${ }^{3}$
}

\section{Resumo}

O objetivo deste estudo foi investigar a microbiota fúngica presente na água potável e no esgoto doméstico de distintos bairros de Santa Maria, Rio Grande do Sul, Brasil. Amostras de água e esgoto foram colhidas durante as quatro estações do ano e analisadas pela técnica de Unidades Formadoras de Colônias (UFC). Foi observada a presença dos gêneros Penicillium, Aspergillus e leveduras nas amostras de água. No esgoto, além dos agentes fúngicos reportados na água foi identificado o gênero Geotrichum. Dessa forma, conclui-se que o tratamento da água realizado no município não é capaz de eliminar estes agentes.

Palavras-chave: Penicillium, Aspergillus, Geotrichum, levedura

\begin{abstract}
The aim of this study was to evaluate the fungal microbiota present in drinking water and domestic sewage from different districts of Santa Maria, Rio Grande do Sul, Brazil. Water and sewage samples were collected during the four seasons and were analyzed by using the technique colony-forming units (CFU). Yeasts and fungi of the genera Penicillium and Aspergillus were observed in the water samples. The genus Geotrichum was also found in the sewage. Therefore, it is concluded that treatment of water held in the municipality is unable to remove these agents.
\end{abstract}

Key words: Penicillium, Aspergillus, Geotrichum, yeast

\footnotetext{
${ }^{1}$ Bolsista de Iniciação Científica da Universidade Federal de Santa Maria, UFSM, Santa Maria, RS. E-mail: sessegolotayana@, gmail.com; camilatochetto@yahoo.com.br

2 Programa de Pós-Graduação na Universidade Federal de Santa Maria, UFSM, Santa Maria, RS. E-mail: regnitro@yahoo.com.br; aleksandro_ss@yahoo.com.br

${ }^{3}$ Departamento de Microbiologia e Parasitologia da Universidade Federal de Santa Maria, UFSM. Faixa de Camobi-Km 9, Campus Universitário, Santa Maria, RS. E-mail: sydneyhazalves@yahoo.com.br; sgmonteiro@uol.com.br; santurio@smail.ufsm.br

* Autor para correspondência
} 
Existem muitas doenças veiculadas pela água que provocam altas taxas de morbidade e mortalidade em pessoas e animais. Pequena parte da população mundial tem acesso à água potável de qualidade e, como consequência, mais de cinco milhões de pessoas morrem anualmente devido às doenças associadas ao consumo de água contaminada e condições sanitárias inadequadas (VINATEAARANA, 1997; ANDRAUS et al., 1999; CHAVES, 2004).

Uma das maiores preocupações dos consumidores com a água considerada potável é a contaminação por micro-organismos patogênicos. Certos organismos, incluindo diversas bactérias, vírus e parasitas, são bem conhecidos contaminantes da água (CHAVES, 2004). A crescente incidência de infecções relacionadas com a ingestão de água tornou-se uma preocupação dominante para as entidades gestoras de sistemas de abastecimento. A água que circula nas redes de distribuição está longe de constituir um produto puro e estável, uma vez que a densidade dos micro-organismos presentes aumenta com o tempo de residência e a distância entre a estação de tratamento e o usuário (CHAVES, 2004).

A ocorrência de fungos na água potável tem recebido atenção crescente nas últimas décadas, devido aos mesmos terem sido incluídos no rol dos contaminantes da água potável. No entanto, a relevância dos fungos aquáticos para a qualidade da água e a saúde humana ainda é pouco compreendida e conflitante (HAGESKAL et al., 2008). No entanto, pesquisadores discutem a ocorrência de alergias e de patologias em pacientes sob terapias imunodepressivas (pacientes com AIDS, por exemplo), quimioterapias e transplantados associadas a infecções fungicas (ESCH, 2004; GONÇALVES et al., 2006).

Nas diversas utilizações da água, em média $80 \%$ resultam em esgoto, seja ele de origem doméstica, hospitalar, industrial, entre outros. O esgoto doméstico ou efluente sanitário contém cerca de $99,9 \%$ de água e $0,1 \%$ de sólidos orgânicos e inorgânicos. Neste, é comum a presença de micro-organismos patogênicos (vírus, bactérias, protozoários, helmintos e fungos leveduriformes), responsáveis por algumas doenças de veiculação hídrica (ANDRAUS et al., 1999).

De acordo com pesquisadores, não é claro ainda na comunidade científica a importância da existência ou detecção de fungos em água potável e esgoto devido aos poucos estudos e sistemática não padronizada entre os laboratórios de ensaios, além de metodologias inadequadas (ANDRAUS et al., 1999; GONÇALVES et al., 2006). Este estudo teve o objetivo de analisar efluentes de esgoto aberto e a água potável de bairros do município de Santa Maria, Rio Grande do Sul, Brasil, quanto à presença de fungos.

As amostras de esgoto foram coletadas em quatro bairros distintos da cidade de Santa Maria onde a população tem contato direto com os efluentes por não haver rede de saneamento público. Nos mesmos locais foram colhidas amostras de água potável, tratada, segundo o órgão responsável (CORSAN). O material foi recolhido nas quatro estações do ano em intervalo de três meses entre os anos de 2007 e 2008. Do esgoto foi coletado água da superfície utilizando um Becker estéril. Já a água potável foi coletada de torneiras da rede de distribuição da CORSAN localizadas em residências sem caixa de água, preconizando-se desprezar os primeiro dois minutos de água corrente, e assim evitar a coleta de água contaminada na torneira.

As amostras de esgoto e água foram armazenadas em recipiente estéril de um litro e conservadas em geladeira. $\mathrm{O}$ total de amostras analisadas no decorrer de um ano foi de 32 , sendo 16 de efluentes e 16 de água tratada. Essas foram analisadas através da técnica de contagens de propágulos fúngicos (UFC), para pesquisa de fungos tanto bolores como leveduras.

A técnica de UFC consiste em colocar $10 \mathrm{ml}$ de água proveniente das amostras em $90 \mathrm{ml}$ de 
água peptonada $0,1 \%$ previamente esterilizada por autoclavação, seguido de incubação em shaker orbital a temperatura ambiente, por 10 minutos. A partir de então foram feitas quatro diluições seriadas, retirando-se $1 \mathrm{ml}$ da amostra inicial e adicionando $9 \mathrm{ml}$ de água peptonada $0,1 \%$, em ambiente estéril. De cada uma das cinco diluições, retirou-se $100 \mu 1 \mathrm{e}$ incubou-se em triplicata em placas de Petri contendo meio apropriado para crescimento fúngico, o ágar Dicloran Rosa de Bengala Cloranfenicol (DRBC), a $27^{\circ} \mathrm{C}$. Para descartar a contaminação ambiental foi utilizada uma placa controle, somente com meio de cultura, mantida em mesmas condições laboratoriais dos bioensaios com água e esgoto. A contagem e identificação das colônias foram realizadas sete dias pós-inoculação.
Foi observado entre as amostras de água potável que $18,7 \%$ estavam contaminadas com o gênero Penicillium, 18,7\% apresentavam leveduras e 6,2\% continham o gênero Aspergillus. Já o esgoto doméstico teve $50 \%$ do material positivo para leveduras, 12,5\% para Penicillium sp., e 6,2\% para Aspergillus sp e Geotrichum sp. (Figura 1). Nas placas controle não ocorreu crescimento de microorganismos, o que da confiabilidade aos resultados e descarta contaminação ambiental. O numero de isolados de fungos na água nas diferentes estações do ano foi semelhante, porém houve diferença entre os bairros pesquisados. A incidência de leveduras na água e no esgoto foi maior no período do verão.

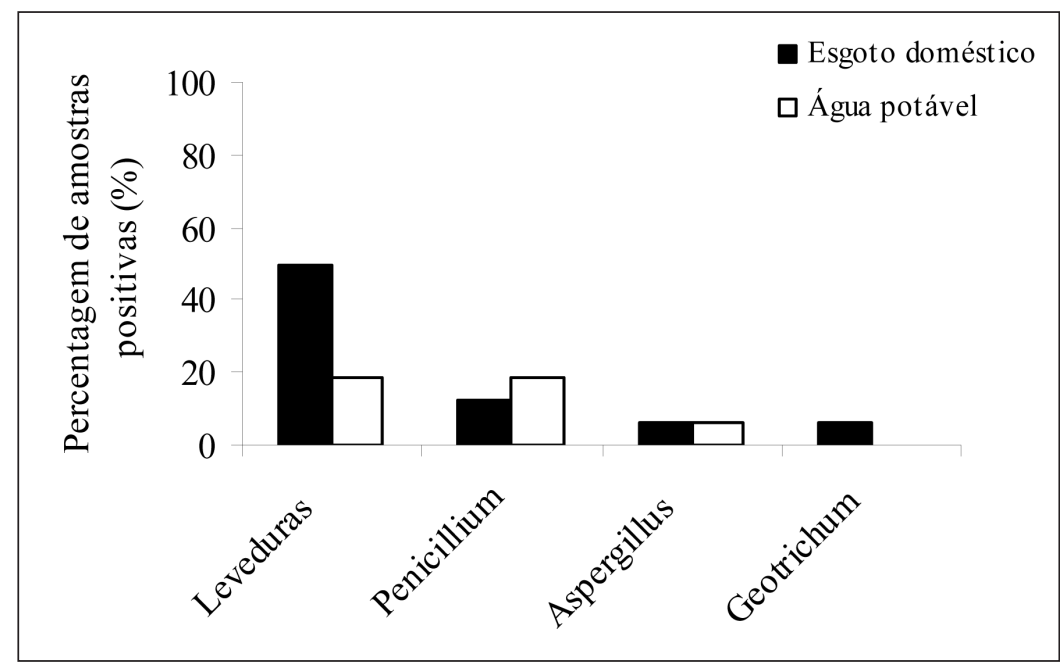

Figura 1. Microbiota fúngica em amostras de esgoto doméstico e água potável em bairros do município de Santa Maria - RS, Brasil, nos anos de 2007 e 2008.

Nas amostras positivas, os valores da UFC/g para o gênero Penicillium na água e no esgoto foram em média de $1,5 \times 10^{4}$ e $5 \times 10^{3}$, respectivamente. Não ocorreu diferença para o gênero Aspergillus na água e no esgoto, a qual foi de $3 \times 10^{3} \mathrm{UFC} / \mathrm{g}$. Na amostra de água do esgoto foi observado $6,6 \times 10^{2}$ UFC/g para Geotrichum sp. Para leveduras, na água potável e no esgoto os valores de UFC foram diferentes, sendo contado em média $2 \times 10^{4} \mathrm{e}$ $7,2 \times 10^{6}$, respectivamente.
Alguns parâmetros físico-químicos são de fundamental importância para sobrevivência dos micro-organismos, dentre eles estão a temperatura, a umidade, a relação carbono/nitrogênio, pois os mesmos necessitam de carbono como fonte de energia e de nitrogênio para síntese de proteínas, e $\mathrm{pH}$, o qual em níveis muito baixos ou muito altos reduzem a atividade microbiana, fatores estes que podem ter interferido nos achados desse estudo. 
O oxigênio é um elemento de essencial importância para organismos aeróbicos, abundante na água (VINATEA-ARANA, 1997). Durante a estabilização aeróbica da matéria orgânica, as bactérias decompositoras fazem uso do oxigênio em seus processos respiratórios, podendo diminuir sua presença no meio. Dependendo da intensidade com que o oxigênio é consumido e da taxa de aeração do ambiente, a ausência de oxigênio pode causar a morte de diversos micro-organismos aquáticos. (PEREIRA, 2004). Portanto, neste estudo isso poderia explicar a menor incidência de fungos no esgoto.

O gênero Penicillium isolado neste estudo tem sido frequentemente encontrado em água (PITT; HOCKING, 1999; GONÇALVES et al., 2006). De acordo com Nunes et al. (2003), fungos como Aspergillus, Penicillium e Fusarium, são considerados importantes produtores de micotoxinas, que são metabólitos tóxicos naturais e freqüentemente encontradas em alimentos. Aproximadamente duzentas espécies de fungos são consideradas toxinogênicas, sendo que o tipo de substrato e as condições do ambiente são fatores determinantes para a produção de micotoxinas. Entre os tóxicos contaminantes de alimentos podemos destacar as aflatoxinas produzidas por espécies do gênero Aspergillus, as quais são altamente tóxicas e carcinogenéticas para homens e animais, tornandose assim, um fator preocupante para a indústria alimentícia. Além disso, a detecção de aflatoxinas produzidas por A. flavus na água de um tanque de armazenamento de água fria foi demonstrada por Paterson, Kelley e Gallagher (1997) e, em estudos in vitro realizados por Kelley et al. (2003) concluíram que micotoxinas e outros metabólitos podem ser produzidas por fungos em água, o que torna a presença de fungos na água um problema de saúde publica. Cabe ressaltar, que a presença de toxinas na água não foi investigada no presente trabalho.

Espécies de Penicillium e Aspergillus não foram identificados neste caso. Porém, a ocorrência de espécies potencialmente patogênicas na água, como o A. fumigatus, tem levantado questionamentos sobre a possibilidade de instalações hidráulicas de hospitais servirem de rota para infecções fúngicas. A hipótese é que fungos presentes na água poderiam ser aerolizados quando a água passasse em locais como torneiras e chuveiros, podendo ocasionar riscos aos pacientes severamente imunocomprometidos. Aumento dos níveis aéreos de Aspergillus e Fusarium tem sido reportado após constante utilização de tais dispositivos (ANAISSIE et al., 2002; WARRIS et al., 2001).

Não existe nenhuma descrição de que os fungos e leveduras isolados nesta pesquisa possam alterar o sabor e odor da água potável. Porém, espécies fúngicas como Chaetomium globosum (KIKUCHI et al., 1981) que produzem geosmina, uma substância que muitas vezes associada a outro composto pode alterar o odor e sabor na água potável (PATERSON; VENÂNCIO; LIMA, 2007). Além disso, fungos podem produzir uma variedade de outros compostos com gostos e sabores distintos (MONTIEL; RIGAL; WELTÉ, 1999). No entanto, a recuperação de fungos a partir de uma fonte de água não significa necessariamente que sua presença na água está causando o problema.

A água potável de Santa Maria nos pontos analisados apresentou contaminantes fúngicos. O esgoto aberto dos bairros tinha presença elevada de leveduras. Não ocorreu diferença entre as estações do ano quanto à presença de fungos, porém constatou-se maior incidência de leveduras no verão, provavelmente devido à maior temperatura da água.

\section{Referências}

ANAISSIE, E. J.; STRATTON, S. L.; DIGNANI, M. C.; SUMMERBELL, R. C.; REX, J. H.; MONSON, T. P.; SPENCER, T.; KASAI, M.; FRANCESCONI, A.; WALSH, T. J. Pathogenic Aspergillus species recovered from a hospital water system: a 3-year prospective study. Clinical Infectious Diseases, Chicago, v. 34, n. 3, p. 780789, 2002. 
ANDRAUS, S.; MEDEIROS, M. L. B.; BORGES, J. C.; SILVA, S. M. C. P.; TOLEDO, E. B. S. Agentes patogênicos: bactérias entéricas. In: ANDREOLI, C. V.; LARA, I. A.; FERNANDES, F. (Ed.). Reciclagem de biossólidos: transformando problemas em soluções. Curitiba: Sanepar Finep, 1999. p. 126-155.

CHAVES, L. C. D. Estudo da cinética de formação de biofilmes em superficies em contacto com água potáve., 2004. Disponível em: $<$ http://repositorium.sdum.uminho. pt/handle/1822/925>. Acesso em: 02 mar. 2009.

$\mathrm{ESCH}, \mathrm{R}$. E. Manufacturing and standardizing fungal allergen products. The Journal of Allergy and Clinical Immunology, Saint Louis, v. 113, n. 2, p. 210-215, 2004.

GONÇALVES, A. B.; RUSSEL, R.; PATERSON, M.; LIMA, N. Survey and significance of filamentous fungi from tap water. International Journal of Hygiene and Environmental Health, Amsterdam, v. 209, n. 3, p. 257264, 2006.

HAGESKAL, G.; VRALSTAD, T.; KNUTSEN, A. K.; SKAAR, I. Exploring the species diversity of tricoderma in norwegian drinking water systems by DNA barcoding. Molecular Ecology Resources, Vancouver, v. 8, n. 6, p. 1178-1188, 2008.

KELLEY, J.; KINSEY, G.; PATERSON, R.; BRAYFORD, D. Identification and control of fungi in distribution systems. Denver: Awwa Research Foundation And American Water Works Association, 2003. 125 p.

KIKUCHI, T.; KADOTAS, S.; SUEHARA, H.; NISHI, A.; TSUBAKI, K. Odorous metabolites of a fungus, Chaetomium globosum: Identificacion of geosmin, a musty-smelling compound. Chemical and Pharmaceutical Bullentin, Japan, v. 29, n. 6, p. 17821784, 1981.
MONTIEL, A.; RIGAL, S.; WELTÉ, B. Study of the origine of musty taste in the drinking water supply. Water Science and Technology, London, v. 40, n. 6, p. 171-177, 1999.

NUNES, I. L.; MAGAGNIN, G.; BERTOLIN, T. E.; FURLONG, E. B. Arroz comercializado na região sul do Brasil: aspectos micotoxicológicos e microscópicos. Ciência e Tecnologia de Alimentos, Campinas, v. 23, n. 2, p. 190-194, 2003.

PATERSON, R. R. M.; KELLEY, J.; GALLAGHER, M. Natural occurrence of aflatoxins and Aspergillus flavus in water. Letters in Applied Microbiology, Oxford, v. 25, n. 6, p. 435-436, 1997.

PATERSON, R. R. M.; VENÂNCIO, A.; LIMA, N. Why do food and drink smell like earth? In: MENDEZ-VILAS, A. (Ed.). Microbiology book series - communicating current reseach and education topics and trends in applied microbiology. Badajoz, Spain: Formatex Press, 2007. p. 120-128.

PEREIRA, R. S. Poluição hídrica causas e conseqüências. Porto Alegre: Instituto de Pesquisas Hidráulicas UFRGS, 2004.

PITT, J. I.; HOCKING, A. D. Fungi and food spoilage. 2. ed. Aspen Publishers: Gaithersburg M. D., 1999.

VINATEA-ARANA, L. Princípios químicos da qualidade da água em aquicultura. Florianópolis: UFSC, 1997. $166 \mathrm{p}$.

WARRIS, A.; GAUSTAD, P.; MEIS, J. F. G. M.; VOSS, A.; VERWEIJ, P. E.; ABRAHAMSEN, T. G. Recovery of filamentous fungi from water in a pediatric bone marrow transplantation unit. Journal of Hospital Infection, London, v. 47, n. 2, p. 143-148, 2001. 
